\title{
Analysis of the effects of exposure to acute hypoxia on oxidative lesions and tumour progression in a transgenic mouse breast cancer model
}

\author{
Tuula M Kalliomäki ${ }^{1,2}$, Gordon McCallum ${ }^{4}$, Sarah Jane Lunt ${ }^{1,2}$, \\ Peter G Wells ${ }^{4}$ and Richard P Hill*1,2,3
}

\begin{abstract}
Address: ${ }^{1}$ Applied Molecular Oncology Division, Ontario Cancer Institute/Princess Margaret Hospital, Canada, ${ }^{2}$ Department of Medical Biophysics, University of Toronto, 610 University Avenue, Toronto, Ontario, M5G 2M9, Canada, ${ }^{3}$ Radiation Oncology, University of Toronto, 610 University Avenue, Toronto, Ontario, M5G 2M9, Canada and ${ }^{4}$ Department of Pharmaceutical Sciences, University of Toronto, 144 College Street, Toronto, Ontario, M5S 3M2, Canada

Email: Tuula M Kalliomäki - tuula.kalliomaki@gmail.com; Gordon McCallum - gordon.mccallum@utoronto.ca;

Sarah Jane Lunt - sarahjanerutherford@gmail.com; Peter G Wells -pg.wells@utoronto.ca; Richard P Hill* - hill@uhnres.utoronto.ca

* Corresponding author
\end{abstract}

Published: 28 May 2008

BMC Cancer 2008, 8:15I doi:10.1 I86/|47|-2407-8-15I

This article is available from: http://www.biomedcentral.com/I47I-2407/8/I5

(C) 2008 Kalliomäki et al; licensee BioMed Central Ltd.

This is an Open Access article distributed under the terms of the Creative Commons Attribution License (http://creativecommons.org/licenses/by/2.0), which permits unrestricted use, distribution, and reproduction in any medium, provided the original work is properly cited.

\begin{abstract}
Background: Tumour hypoxia is known to be a poor prognostic indicator, predictive of increased risk of metastatic disease and reduced survival. Genomic instability has been proposed as one of the potential mechanisms for hypoxic tumour progression. Both of these features are commonly found in many cancer types, but their relationship and association with tumour progression has not been examined in the same model.
\end{abstract}

Methods: To address this issue, we determined the effects of 6 week in vivo acute hypoxic exposure on the levels of mutagenic lipid peroxidation product, malondialdehyde, and 8-oxo-7,8dihydro-2'-deoxyguanosine DNA (8-oxo-dG) lesions in the transgenic polyomavirus middle T (PyMT) breast cancer mouse model.

Results: We observed significantly increased plasma lipid peroxidation and 8-oxo-dG lesion levels in the hypoxia-exposed mice. Consumption of malondialdehyde also induced a significant increase in the PyMT tumour DNA lesion levels, however, these increases did not translate into enhanced tumour progression. We further showed that the in vivo exposure to acute hypoxia induced accumulation of F4/80 positive tumour-associated macrophages (TAMs), demonstrating a relationship between hypoxia and macrophages in an experimental model.

Conclusion: These data suggest that although exposure to acute hypoxia causes an increase in 8oxo-dG lesions and TAMs in the PyMT tumours, these increases do not translate into significant changes in tumour progression at the primary or metastatic levels in this strong viral oncogenedriven breast cancer model. 


\section{Background}

Hypoxia in tumours is a predictor of poor patient survival. This has been shown most extensively in soft tissue sarcoma, and in cervical and head and neck carcinoma patients where tumour hypoxia, as assessed by partial pressure of oxygen $\left(\mathrm{pO}_{2}\right)$ measurements, is predictive of metastatic and/or disease-free survival [1]. In breast cancer patients the role of hypoxia as a predictor for survival has been demonstrated through immunohistochemical detection of hypoxia-dependent markers, such as hypoxiainducible factor- $1 \alpha$ (HIF- $1 \alpha$ ) and carbonic anhydrase IX (CAIX) [2,3].

The underlying mechanisms for hypoxia-mediated tumour progression are not well understood. Examinations of the effects of different types of tumour hypoxia on metastatic progression have suggested acute (cycling) hypoxia to be more important than chronic (diffusion limited) hypoxia [4,5]. A potential association between acute hypoxia and genomic instability has been suggested by Comet assay data, which showed significantly increased numbers of single-strand DNA breaks in tumour samples from mice exposed to acute hypoxia compared with samples from mice exposed to chronic hypoxia (Cairns and Hill, unpublished data, 2004). Similar data has been reported in tumour cells exposed to increased number of hypoxic cycles in vitro, which resulted in increased number of DNA mutations, the frequency and types of which resembled those found in the same cells grown as tumours in vivo [6]. In vitro hypoxia exposure can also mediate larger scale genomic instability by increasing fragile site induction, gene amplification and cellular DNA content [7-9].

In some cases genomic instabilities in hypoxic tumours have been attributed to hypoxia-mediated inhibition of various DNA repair mediators from the homologous recombination, mismatch repair and non-homologous end joining DNA repair pathways [10-13]. However, the role of reactive oxygen and nitrogen species (ROS, RNS) in tumour progression as mediators of a "mutator phenotype" is also well documented $[14,15]$ and acute hypoxia is known to generate these species through multiple systems including mitochondria, xanthine oxidase, ferrylhemoglobin, NADPH oxidase and thymidine phosphorylase $[16,17]$. Upon reaction with DNA, free radicals can generate mutagenic DNA lesions, such as 8oxo-dG, that cause $\mathrm{GC} \rightarrow \mathrm{TA}$ transversions and structural changes compromising the transcriptional fidelity of the genome [18]. DNA damage can also be induced indirectly through free radical reaction with polyunsaturated fatty acids of cellular membranes and formation of lipid peroxidation products such as, isoprostanes, 4-hydroxynonenal and malondialdehyde (MDA), shown to induce frameshift mutations and base pair substitutions $[19,20]$.
Macrophages (MØs), which have been reported to be attracted to hypoxic tumour areas, are also a source of mutagenic superoxide $\left(\mathrm{O}_{2}^{-}\right)$, nitric oxide (NO) and peroxynitrite (ONOO-) species [21,22]. In tumours, the MØs can promote tumour cell angiogenesis, invasion and survival by up-regulating genes such as GLUT-1, VEGF, CXCR4 and MIF [23] and high levels of these tumourassociated macrophages (TAMs) can predict poor patient survival [24]. In support of the concept of TAM-mediated tumour progression, Pollard and colleagues showed that reducing the number of TAMs in the polyoma middle $\mathrm{T}$ (PyMT) breast cancer model by crossing it to op/op null mice with a mutation in the colony stimulating factor- 1 (CSF-1) gene, inhibited metastasis formation [25]. Further studies in the same model demonstrated that tumour cell movement and intravasation occur most frequently when the tumour cells are within $20 \mu \mathrm{m}$ of a perivascular TAM [26].

In this study we examined the effect of acute (cyclic) hypoxia on tumour progression in relation to oxidative stress, TAMs and genomic instability in the MMTV-PyMT model. We demonstrated significantly increased levels of 8-oxo-dG lesions and TAM content in tumours from mice exposed to acute hypoxia but these increases did not translate into significant changes in tumour progression.

\section{Methods \\ Animals}

A breeder pair of mice with a PyMT transgene under the MMTV promoter (MMTV-PyMT634Mul), originally described by Guy et al., was obtained from Dr. Rama Khokha (Princess Margaret Hospital, Ontario Cancer Institute, Toronto, Canada) [27]. The mice were bred and maintained at the Animal Resource Centre of the Ontario Cancer Institute in compliance with the guidelines of the Canadian Council on Animal Care. Tissue samples were obtained at 2 weeks-of-age and screened for the presence of the PyMT transgene using the following primers (forward) 5' GGA AGC AAG TAC TTC ACA AGG 3' and (reverse) 5' GGA AAG TCA CTA GGA GCA GGG 3'. Mice were weaned at 3 weeks-of-age. All experiments were conducted with heterogeneous, virgin MMTV-PyMT or littermate wild type (WT) mice.

\section{Hypoxia, malondialdehyde and 2-nitropropane treatments}

For acute hypoxia $(\mathrm{AH})$ experiments, mice were treated 5 times a week for 6 weeks, from 3 to 9 weeks-of-age. The hypoxia exposure consisted of 12 cycles of $10 \mathrm{~min}$ of air, followed by $10 \mathrm{~min}$ of $7 \%$ oxygen, balance nitrogen for a daily total of 4 hours, in airtight chambers as described previously [4]. Air control (AC) animals were exposed to a daily total of 4 hours of air in separate sealed chambers and cage control (CC) animals were left in their cages 
untouched. For HPLC and immunohistochemical analyses, mice were killed within 1 hour following the last gassing exposure at the age of 9 weeks to ensure similar tumour development for mammary tissues from mice treated for 4 hours/day during 1 day, 5 days or 6 weeks. For the tumour progression studies, the mice were left in their cages following the 6-week exposure until they reached the age of 88 days at which time the experiment was terminated and primary tumour growth and metastases were assessed. For determination of tumour hypoxia levels, mice were injected intraperitoneally $(10 \mathrm{mM}, 0.01$ $\mathrm{mL} / \mathrm{g}$ ) with the exogenous hypoxia marker, EF5 ([2-(2nitro-1H-imidazol-1-yl)-N-(2,2,3,3,3-pentafluoropropyl acetamide], Dr. Cameron Koch, University of Pennsylvania), 1 hour into the 4 hour gassing exposure during a reoxygenation cycle and killed within 1 hour of the last hypoxic cycle.

Animals treated with the lipid peroxidation product, malondialdehyde, (MDA, Sigma-Aldrich) received acidified water with $10 \mathrm{mM}$ MDA, replaced twice a week while control animals (MDA-CC) received normal acidified water. The drug concentration was based on a measured average daily water consumption of $3.75 \mathrm{~mL} /$ mouse/day and calculated to give an approximate daily dose of 250 $\mathrm{mg} / \mathrm{kg}$ [28]. Mice received the treated water for 6 weeks, from 4 to 10 weeks-of age at which point they were killed if used for HPLC analysis or left to develop their tumours to the age of 81 days if used for tumour progression analysis. An oxidizing agent, 2-nitropropane (2-NP, SigmaAldrich), reported to increase the number of 8-oxo-dG lesions in mice, was used as a positive control for the HPLC analyses [29]. It was administered intraperitoneally at $167 \mathrm{mg} / \mathrm{kg}$ in sterile olive oil vehicle and the mice were sacrificed 24 hours after a single dose at the age of 81 days.

\section{Immunohistochemistry (IHC)}

Snap frozen tumour tissue from hypoxia-exposed mice was used for IHC staining of markers for macrophages (F4/80; ab6640: 1/300 1 hr R/T; Abcam Inc., Cambridge, MA), base excision repair (APE/Ref-1; ab82: 1/100 O/N $4{ }^{\circ} \mathrm{C}$; Abcam Inc., Cambridge, MA), hypoxia (EF5; ELK351: 1/50 O/N R/T; Dr. Cameron Koch, University of Pennsylvania) and vasculature (CD31; MEC13.3: 1/500 $1 \mathrm{hr}$ R/ $\mathrm{T}$; BD Pharmingen) according to manufacturer's instructions. Total area of positive staining in tumour sections, (1 per tumour, of approximately $43 \mathrm{~mm}^{2}$ ) with areas of necrosis and connective tissue excluded, was quantified with the positive pixel algorithm by Aperio ImageScope (Aperio Technologies, Vista, CA). Inter-mouse variability of EF5 staining was quantified in 31 tumours from 11 different mice.

\section{Assessment of primary and metastatic tumour burdens}

In $\mathrm{AH}$ experiments primary tumour burden and the number of lung metastases were determined in 88-dayold mice. This time was reduced by a week to 81 days for MDA experiments to reduce the tumour burden prior to sacrifice since the MMTV-PyMT mice develop multiple primary tumours. The primary tumour burden was obtained by multiplying tumour length $\times$ tumour width and summing the individual tumour values of each mouse. Lungs were fixed in 10\% neutral buffered formalin for 48 hours and then transferred to $70 \%$ ethanol. Macroscopic lung metastases in individual lung lobes were scored under a dissecting microscope. Micrometastases in each pair of lungs were summed from 4 sections (separated by $100 \mu \mathrm{m}$ ) stained with haematoxylin and $\operatorname{eosin}(\mathrm{H}+\mathrm{E})$.

\section{Lipid peroxidation (TBARS) and antioxidant reductive capacity assays}

Heparinized blood from hypoxia- and control-exposed mice was centrifuged at $6000 \mathrm{rpm}$ for $1 \mathrm{~min}$. The separated plasma was divided into 2 aliquots to prevent repeated freezing and thawing of the sample and stored at $-80^{\circ} \mathrm{C}$ until analysis. Plasma samples were analysed with the thiobarbituric acid reactive substance (TBARS) assay, which measures MDA by reaction with thiobarbituric acid to form a red product that was quantified spectrophotometrically. MDA was quantified in $150 \mu \mathrm{L}$ of plasma with $5 \mu \mathrm{l}$ of $0.1 \mathrm{M}$ butylated hydroxytoluene (BHT, SigmaAldrich). Following the addition of $62.5 \mu \mathrm{L}$ of pure glacial acetic acid and $62.5 \mu \mathrm{L}$ of $0.67 \%$ thiobarbituric acid (Sigma-Aldrich), the samples were incubated at $50^{\circ} \mathrm{C}$ for 2 hours and cooled to room temperature for extraction of the coloured reaction product with $1 \mathrm{~mL}$ of 1-butanol, which was read with a spectrophotometer at $535 \mathrm{~nm}$ [30].

The antioxidant status of the plasma from $\mathrm{AH}$ and $\mathrm{AC}$ exposed mice was assayed with an antioxidant reductive capacity assay (NWK-ARC01; Northwest Life Science Specialties, Vancouver, WA). This 96-well assay is based on the ability of sample antioxidants to reduce $\mathrm{Cu}^{++}$to $\mathrm{Cu}^{+}$, which reacts with bathocuproine to form a coloured product, read at $492 \mathrm{~nm}$. Plasma samples from 10-11 mice were assayed in triplicate.

\section{Quantification of 8-oxo-7,8-dihydro-2'-deoxyguanosine lesions in DNA}

DNA isolation and purification

The DNA extraction protocol was based on work published by Ravanat et al. [31]. Briefly, the snap frozen tumour samples were thawed on ice, homogenized with 1 $\mathrm{mL}$ of lysis buffer A (10 mM Tris-HCl, $320 \mathrm{mM}$ sucrose, 5 $\mathrm{mM} \mathrm{MgCl}_{2}, 0.1 \mathrm{mM}$ desferroxamine, $1 \%$ Triton X-100, $\mathrm{pH}$ 7.5) and centrifuged at $1,000 \mathrm{~g}$ for $10 \mathrm{~min}$ to isolate the nuclear pellet. The pellet was washed once in lysis buffer 
A and resuspended into $200 \mu \mathrm{L}$ of buffer B (10 mM Tris$\mathrm{HCl}, 1 \% \mathrm{w} / \mathrm{v}$ SDS, $5 \mathrm{mM}$ EDTA-NA, $0.15 \mathrm{mM}$ desferroxamine, pH 8.0) using a plastic Kontes Pellet Pestle ${ }^{\circledast}$. RNA was digested by adding $13.3 \mu \mathrm{l}$ of a $50 \mathrm{U} / \mathrm{mL}$ RNase A and $100 \mathrm{U} / \mathrm{mL}$ RNase $\mathrm{T}$ solutions for $1 \mathrm{hr}$ at $50^{\circ} \mathrm{C}$. A proteinase $\mathrm{K}$ solution $(13.3 \mu \mathrm{l} ; 5 \mathrm{mg} / \mathrm{mL})$ in $10 \mathrm{mM}$ Tris $/ 1 \mathrm{mM}$ EDTA, pH 7.4 was added for protein digestion at the same incubation conditions. Prior to the DNA extraction, the samples were centrifuged at $10,000 \mathrm{~g}$ for $10 \mathrm{~min}$ to remove any undigested tissue. DNA was precipitated with $0.3 \mathrm{~mL}$ of Buffer C (40 mM Tris- $\mathrm{HCl}, 7.6 \mathrm{M} \mathrm{NaI}, 20 \mathrm{mM}$ EDTA-NA $2,0.3 \mathrm{mM}$ desferroxamine, $\mathrm{pH} 8.0$ ) and $0.5 \mathrm{~mL}$ of $100 \%$ isopropanol. The precipitate was centrifuged at $10,000 \mathrm{~g}$ and washed 4 times with $70 \%$ ethanol. The DNA pellet was resuspended in $20 \mathrm{mM} \mathrm{Na}$-acetate buffer with $0.1 \mathrm{mM}$ desferroxamine, $\mathrm{pH}$ 5.2. Diluted DNA samples were digested with $5 \mathrm{U}$ of nuclease $\mathrm{P} 1$ prepared in $20 \mathrm{mM}$ Na-acetate buffer. The pH was adjusted to 8.5 with $1 \mathrm{M}$ Tris-HCl buffer and the DNA hydrolyzed to nucleosides by incubation with $6 \mathrm{U}$ of calf intestine alkaline phosphatase (Roche Diagnostics, Laval, PQ) for $1 \mathrm{hr}$ at $37^{\circ} \mathrm{C}$. The suspension was transferred to Microcon ${ }^{\circledR} \mathrm{YM}-10$ spin columns (Millipore, Mississauga, ON) and centrifuged at $10,000 \mathrm{~g}$ for $30 \mathrm{~min}$, filter-sterilized and injected for HPLC analysis.

\section{HPLC conditions}

The HPLC system (200 series, Perkin Elmer, Woodbridge, $\mathrm{ON}$ ) consisted of a $0.2 \mu \mathrm{m}$ mobile phase filter, a vacuum degasser, an isocratic HPLC pump set at $1.0 \mathrm{~mL} / \mathrm{min}$, an autosampler with a $200 \mu \mathrm{L}$ sample loop and a Spherisorb ${ }^{\circledR}$ ODS-2 guard column $(10 \times 4.6 \mathrm{~mm}$ i.d., $5 \mu \mathrm{m}$, Waters, Mississauga, ON), and 2 Spherisorb ${ }^{\circledR}$ ODS-2 analytical columns $(150 \times 4.6 \mathrm{~mm}$ i.d., $5 \mu \mathrm{m}$, Waters, Mississauga, $\mathrm{ON})$ connected in series. The mobile phase consisted of $7.5 \%$ methanol, and $50 \mathrm{mM}$ sodium phosphate buffer, $\mathrm{pH} 5.5$, filtered through a $0.2 \mu \mathrm{m}$ filter (Millipore, Mississauga, ON). The 8-oxo-dG was detected with an electrochemical detector (Coulochem II 5200A, ESA, Chelmsford, MA) with a PEEK-filter protected analytical cell (5010, ESA; 10nA; screen electrode $+100 \mathrm{mV}$; analytic electrode, $+400 \mathrm{mV})$. The $\mathrm{dG}$ was detected with a UV detector (200 series, Perkin Elmer, Woodbridge, ON) set at $280 \mathrm{~nm}$. Data were recorded using a NCI 902 dual detector interface and analyzed with Totalchrom Workstation Ver 6.3.1 software (Perkin Elmer, Woodbridge, ON). Levels of 8-oxo-dG and dG in samples were quantified via calibration curves with authentic standards.

\section{Statistical analysis}

For non-parametric data sets, such as those for metastases, the Kruskal-Wallis test with Dunn's correction for multiple comparisons was performed on experiments with 3 or more groups and the Mann-Whitney test was performed on experiments with 2 groups. For parametric data sets with equal variances, such as those for tumour burden, ANOVA with Bonferroni correction was performed on experiments with 3 or more groups and Student's t-test was performed on experiments with 2 groups. Mixed modelling was used to correct for inter-experimental variability in repeat TBARS assays.

\section{Results \\ Lowering of tumour oxygenation with in vivo acute hypoxia gassing regime}

The hypoxia marker EF5 was used to identify hypoxic areas in the MMTV-PyMT tumours (Figure 1A). Although the overall values of EF5 positive areas were relatively low, the total median EF5 positive area was significantly greater in tumours from mice exposed to 6 weeks of $\mathrm{AH}$ than $\mathrm{AC}$ gassing (Figure $1 \mathrm{~B} ; \mathrm{P}<0.05$ ). Interestingly, intertumour variability in EF5 positive areas of individual animals was substantial, varying from $0.3 \%$ to $8.1 \%$ per mouse.

\section{Oxidative stress and genomic instability in hypoxia- and MDA-treated mice}

To determine the extent of oxidative stress induced by the gassing, plasma was obtained from transgenic and WT mice following the 6 -week gassing regime. Mean plasma TBARS levels were greater in mice exposed to $\mathrm{AH}$ than in animals exposed to AC in 3 separate experiments, a difference that was shown to be significant with mixed modelling analysis $(\mathrm{P}<0.0005)$. TBARS levels in mice drinking MDA-supplemented water were also significantly increased relative to both gassing groups (Table 1). Oxidative stress was also assessed by HPLC quantification of 8oxo-dG lesions. Tumour samples from mice exposed to $\mathrm{AH}$ showed an increasing difference relative to AC mice over the 1 day, 5 day and 6 week exposures. The difference was significant by the 6 week time point $(P<0.05)$. MDA consumption increased tumour 8-oxo-dG lesions significantly at all time points (Figure 2).

\section{Effects of acute hypoxia and MDA on primary and metastatic tumour progression}

To address the question on how MDA or hypoxia would affect tumour progression of the MMTV-PyMT model, primary and metastatic tumour burdens were quantified in mice exposed to these conditions. MDA consumption, which resulted in a significant increase in 8-oxo-dG lesion levels, did not significantly alter any of the tumour progression parameters examined (Figures $3 \mathrm{~A}-\mathrm{C}$ ). The primary tumour burden following $\mathrm{AH}$ exposure also remained unaffected relative to AC mice, although both $\mathrm{AC}$ and $\mathrm{AH}$ groups had significantly reduced primary tumour burdens relative to unexposed CC mice (Figure $3 \mathrm{~A})$. The numbers of macroscopic metastases showed the same range and no significant differences between the AC, $\mathrm{AH}$ and CC groups (Figure 3B). 

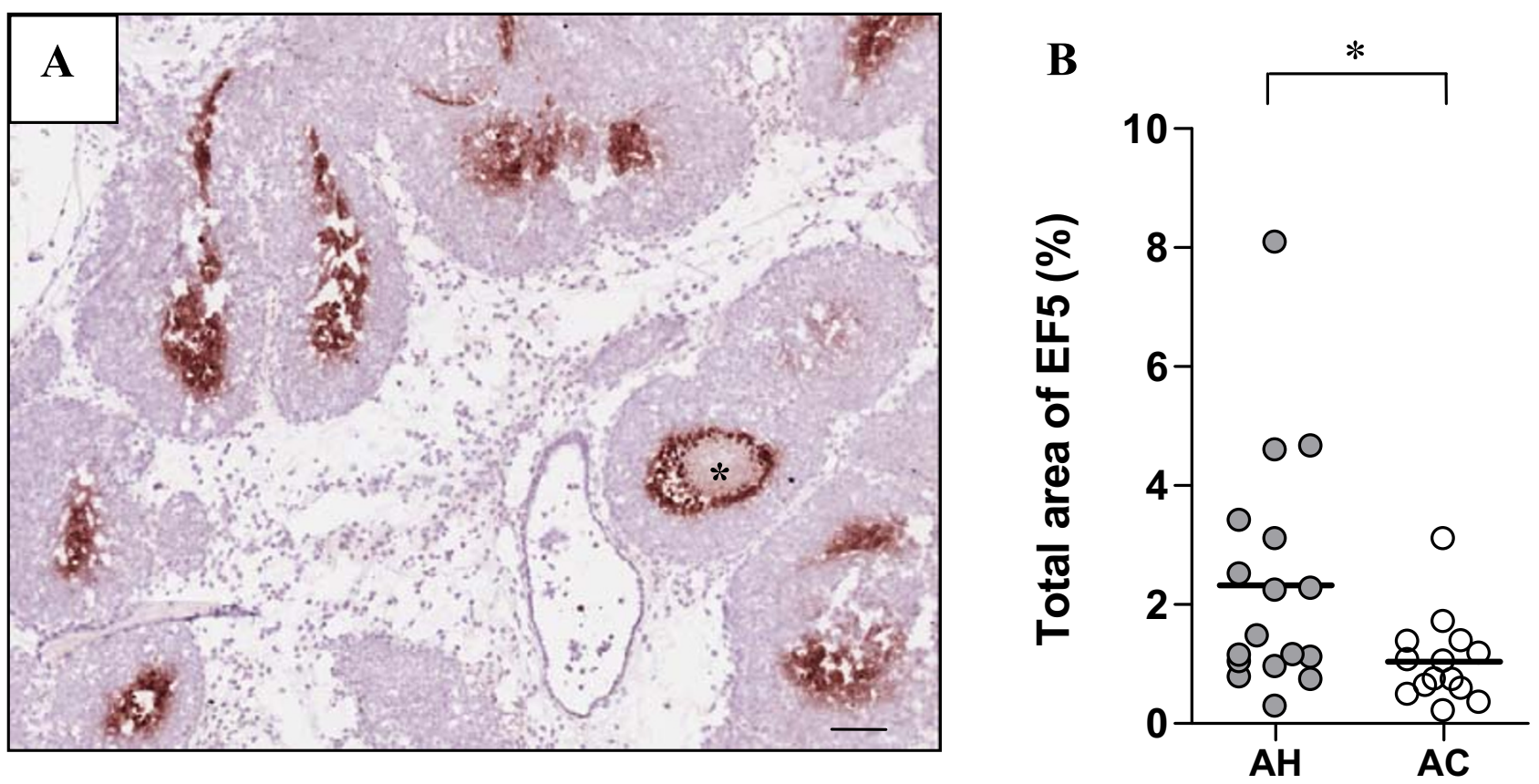

Figure I

Levels of EF5 following 4 hours of in vivo acute hypoxia exposure. (A) An H+E stained tumour section from a PyMT mouse tumour with EF5 positive hypoxic areas stained in brown, necrotic tumour core is marked with an asterix. Scale bar: $100 \mu \mathrm{m}$. (B) Quantification of total EF5 positive staining area (\%) in 3 I tumours from I I PyMT mice exposed to AC or AH conditions for 4 hours showed significantly greater median levels of hypoxia in mice exposed to $\mathrm{AH}$ than in mice exposed to $\mathrm{AC}(\mathrm{P}<0.05 ; *)$.

\section{Total antioxidant capacity and APE/Ref-I levels in hypoxia treated mice}

To determine whether altered antioxidant levels in $\mathrm{AH}$ exposed mice may have been the underlying reason for the small increase in 8-oxo-dG lesions, the total antioxidant capacity of plasma from the $\mathrm{AC}$ and $\mathrm{AH}$ mice was assessed. Plasma from AH-exposed mice showed a trend of reduced antioxidant reductive capacity relative to plasma from AC mice (Figure 4A; $\mathrm{P}=0.0667$ ). Assessment of the relationship between plasma antioxidant capacity and tumour 8-oxo-dG lesions revealed a significant corre- lation between these parameters in the AC group (Figure $\left.4 \mathrm{~B} ; \mathrm{r}^{2}=0.9094, \mathrm{P}<0.05\right)$, which did not occur with the hypoxia exposure.

$\mathrm{APE} /$ Ref-1 is a multifunctional protein that acts as an endonuclease in the BER pathway and controls the activity of transcription factors, such as AP- 1 and HIF- $1 \alpha$ by regulating their state of oxidation. Cellular localization of APE/Ref-1 is generally found to be ubiquitous, but varying between nuclear and cytoplasmic compartments [32]. APE/Ref-1 staining in the MMTV-PyMT tumours was pri-

Table I: TBARS plasma lipid peroxidation levels following oxidative stresses

\begin{tabular}{lccc}
\hline & & Absorbance values (Arbitrary scale) \\
\cline { 2 - 4 } & Air Control (AC) & Acute Hypoxia (AH) & Ratio (AH/AC) \\
\hline Expt I $(\mathbf{n}=\mathbf{4 - 5})$ & $0.080+/-0.005$ & $0.101+/-0.007$ & 1.27 \\
Expt $2(\mathbf{n}=\mathbf{7})$ & $0.132+/-0.006$ & $0.152+/-0.008$ & 1.16 \\
Expt $3(\mathbf{n}=\mathbf{8 - 9})$ & $0.048+/-0.002$ & $0.060+/-0.004$ & 1.24
\end{tabular}

Lipid peroxidation assessed by TBARS assay in plasma of transgenic mice treated with 6 weeks of acute hypoxia (AH) showed a significantly increased plasma absorbance levels relative to air control $(A C)$ conditions in 3 repeat assays (mixed modelling analysis on combined data; $P$ < 0.0005). Lipid peroxidation in plasma of positive control WT animals drinking MDA-supplemented acidified water for 6 weeks was significantly increased relative to both $A H-(P<0.0 I)$ and $A C-(P<0.00 I)$ exposed mice. Mean $+/-S E M$ are shown for each experimental group. 


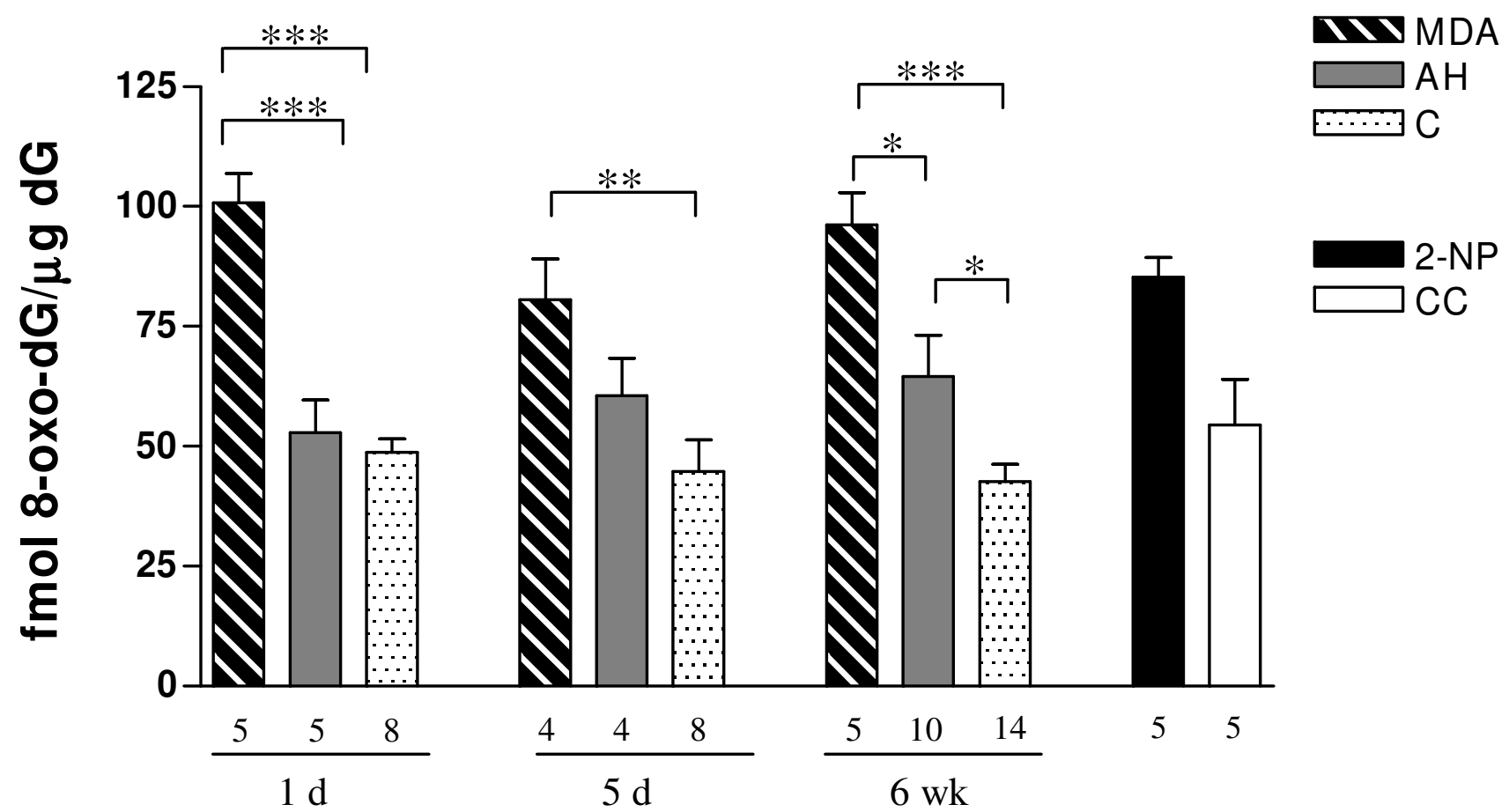

Figure 2

Tumour 8-oxo-dG lesion levels following oxidative stresses. Mutagenic 8-oxo-dG lesions quantified at I day time point resulted in significant changes between MDA and AH and MDA and $C(P<0.001$; ***) groups. Following 6 weeks of treatment the lesion levels were significantly increased in $\mathrm{AH}$ mice relative to $A C$ mice $\left(P<0.05 ;{ }^{*}\right)$. Legends: $M D A=$ malondialdehyde; $\mathrm{AH}=$ acute hypoxia; $\mathrm{C}=$ pooled controls from air control and PBS injected groups; 2-NP = positive control, 2-nitropropane; $\mathrm{CC}=$ cage control. Bars: mean with SEM. Number of tumours used for each group is indicated below the bars.

marily localized to the connective tissue (Figure 4C). In tumour cells, the staining levels were generally low and primarily cytoplasmic and were not found to differ between the two treatment groups. Image analysis was conducted in tumour tissues only and in tumour with connective tissue included, but neither analysis showed a difference between $\mathrm{AH}$ - and AC-exposed mice (Figure 4D).

\section{Effects of hypoxia on TAMs and vasculature}

TAMs have been previously reported to be involved in tumour progression in the MMTV-PyMT model and to accumulate in hypoxic areas $[21,25,26]$. To quantify TAM content, tumour samples were stained with the $M \varnothing$ marker F4/80. Interestingly, the F4/80 positive staining was seen evenly throughout the tumours in contrast to the highly localized staining pattern commonly seen with extrinsic hypoxia markers such as EF5 (cf. Figures 1A and $5 \mathrm{~A}$ ). The overall levels of F4/80 were significantly increased in samples from hypoxia-relative to air-exposed mice (Figure 5B; $\mathrm{P}<0.05$ ). TAMs have been reported to have pro-angiogenic effects $[33,34]$ and therefore tumour vasculature was quantified through CD31 staining (Figure 5C). Similarly to our previous in vivo acute hypoxia study in a cervical tumour model the total area of CD31 positive staining was significantly reduced following $\mathrm{AH}$ exposure despite the increase in TAMs [35] (Figure 5D; $\mathrm{P}<0.01$ ).

\section{Discussion}

Hypoxia has been reported to enhance metastatic tumour progression and to be associated with oxidative stress, genomic instability and TAMs [21,36-38]. We have previously shown metastasis-promoting effects of in vivo acute hypoxia in a murine fibrosarcoma and a human orthotopic cervical model [4,35] and in the current study, we examined the relationships between the above parameters in an in vivo transgenic breast cancer model with high metastatic potential.

In human breast cancer, the mutagenic end product of lipid peroxidation, MDA, is commonly used as a marker for oxidative stress $[19,39]$, which in turn has been associated with induction of epithelial cell invasiveness and metastatic phenotype $[40,41]$. In our study, TBARS assay of plasma for lipid peroxidation products from mice exposed to $\mathrm{AH}$ shows a significant increase relative to $\mathrm{AC}$ mice. The increased level of oxidative stress following $\mathrm{AH}$ exposure was further supported by the trend of reduced 

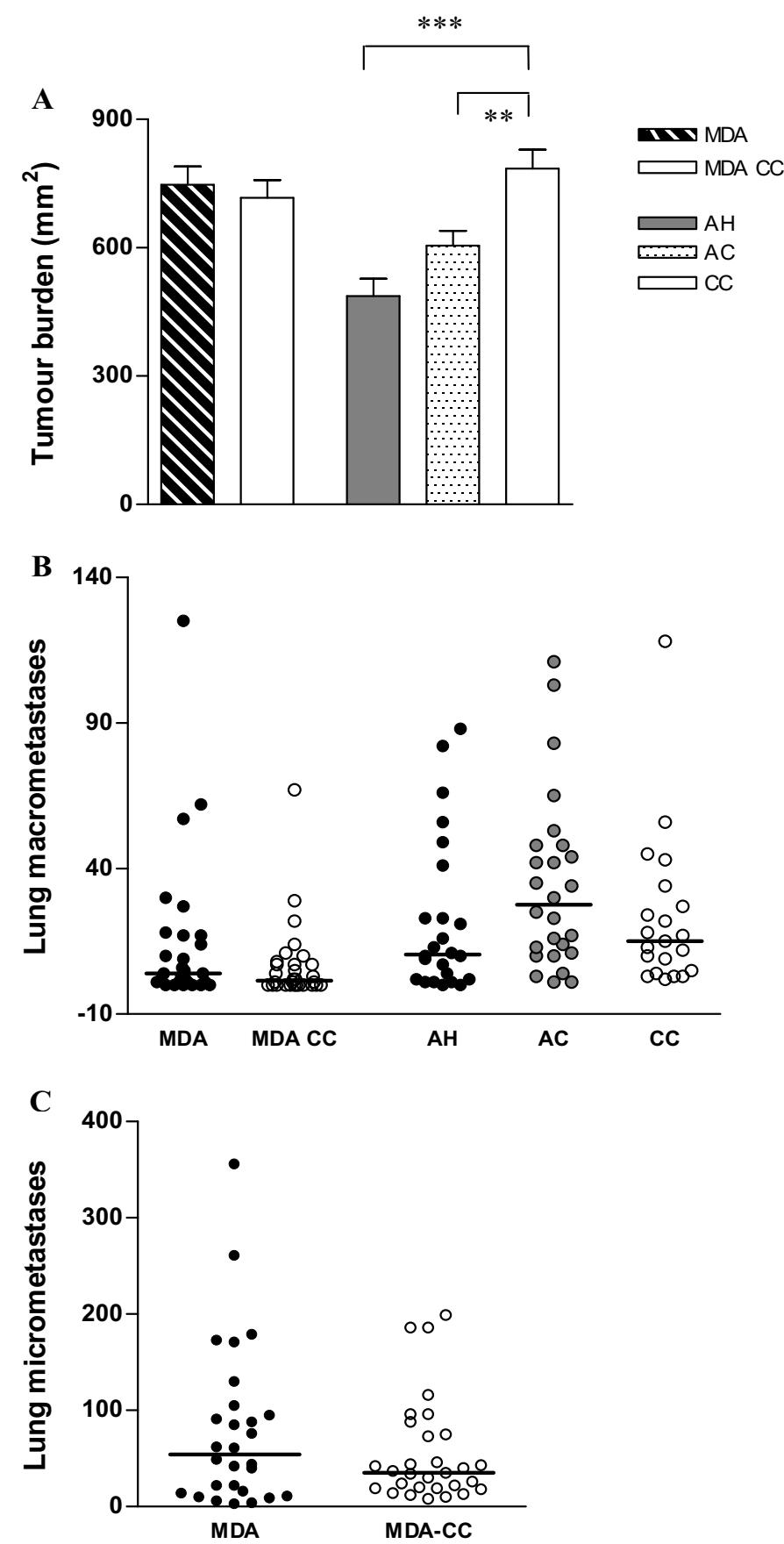

Figure 3

Primary and metastatic tumour progression in MDA- and AH - exposed mice. (A) CC mice developed significantly larger primary tumours than mice exposed to $\mathrm{AH}(\mathrm{P}<0.00 \mathrm{I}$; ***) or $\mathrm{AC}$ conditions $(\mathrm{P}<0.01$; **). Six-week exposure to MDA did not affect the size of endpoint tumour burden relative to MDA-CC. (B) MDA or AH exposure during primary tumour development did not increase macroscopic lung metastases relative to their respective controls. (C) A trend towards an increased number of micrometastases was seen following MDA consumption. Micrometastases were not assessed in the hypoxia experiment due to a large number of macroscopic metastases. Abbreviations: MDA = malondialdehyde $(n=28)$ and MDA-CC = cage controls for MDA group $(n=30), 81$ days; $A H=$ acute hypoxia $(n=24), A C=$ air control $(n=26)$ and $C C=$ cage controls for AH group $(n=20)$, 88 days. Bars: mean with SEM $(A)$, medians ( $B$ and $C)$. Number of animals used for each group is indicated in parentheses. 

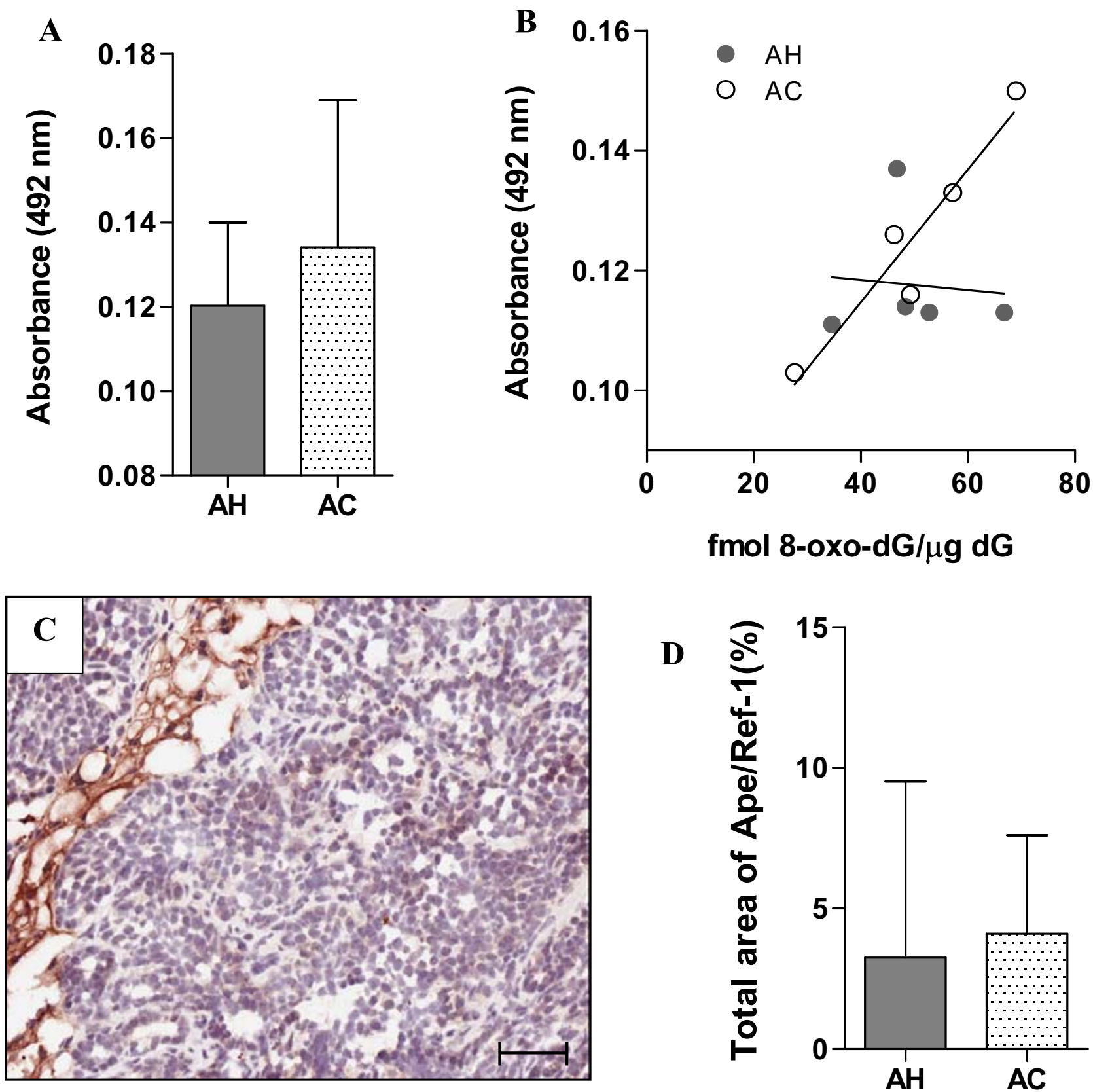

Figure 4

Total plasma antioxidant capacity and tumour APE/Ref-I expression. (A) Plasma samples from mice exposed to AH showed a trend of reduced levels of total antioxidant reductive capacity relative to AC mice. (B) Scatter plot of total antioxidant reductive capacity and 8-oxo-dG lesions in matching samples showed a significant positive correlation for AC mice $\left(r^{2}=\right.$ 0.9094; $P<0.05)$, which was absent in the AH samples $\left(r^{2}=0.008383 ; P=0.8836\right)$. (C) BER protein, APE/Ref-I was expressed predominantly in the connective tissue of the MMTV-PyMT tumours. (D) Total positive staining area for APE/Ref-I in tumour tissue (excluding connective tissue) did not differ in tissues from acute hypoxia and air control exposed mice. Bars: median with interquartile range. Scale bar: $50 \mu \mathrm{m}$. 

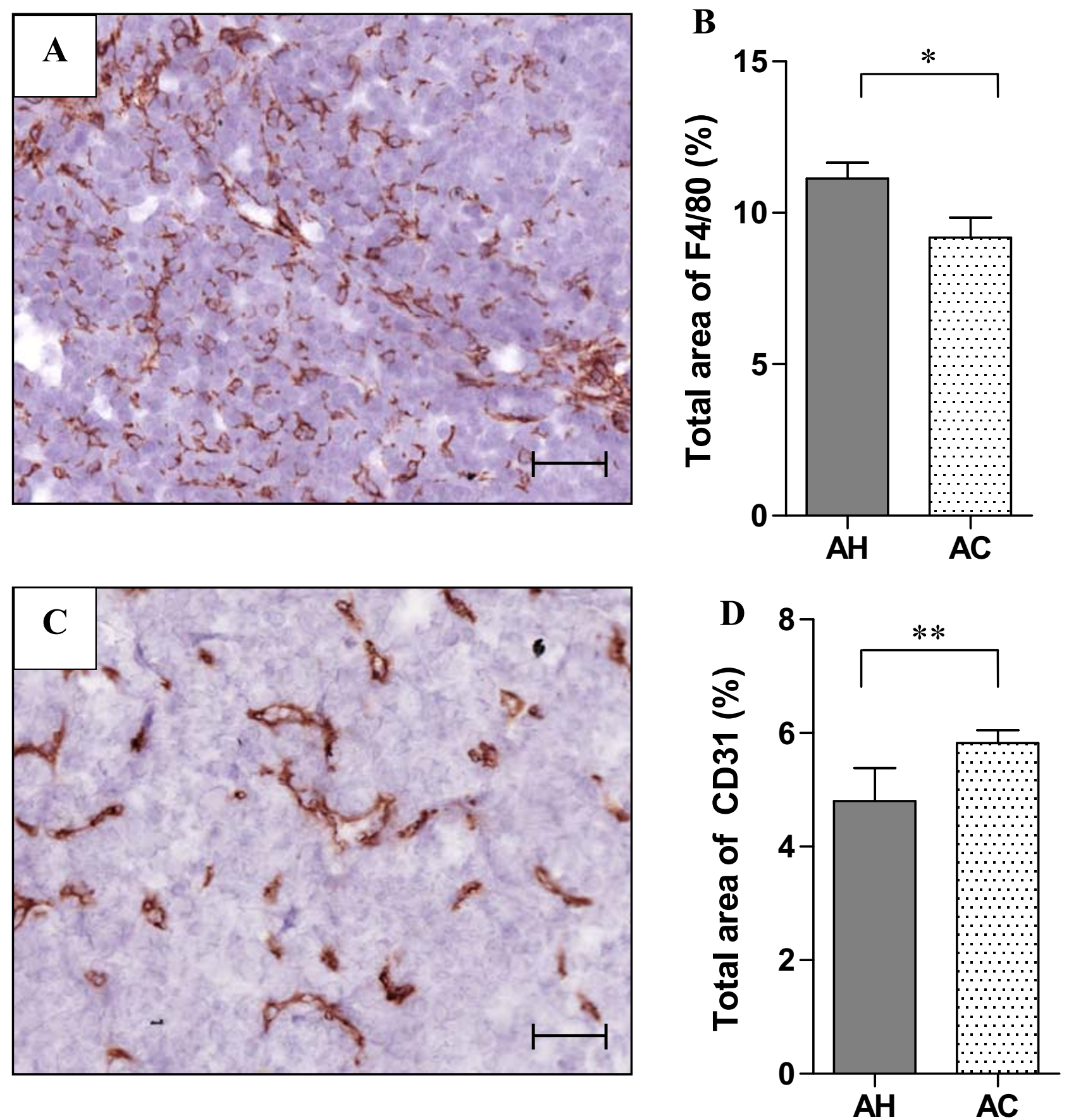

Figure 5

Quantification of TAM and vascular markers. (A) Representative cytoplasmic expression of M $\varnothing$ marker F4/80 in a MMTV-PyMT tumour section. (B) Total positive staining area of F4/80 was significantly higher in AH than AC treated animals $(P<0.05 ; *)$. (C) Representative staining pattern of vascular marker CD3 I in MMTV-PyMT tumours. (D) Total CD3 I positive area was significantly reduced following hypoxia exposure $(\mathrm{P}<0.0 \mathrm{I}$; **). $\mathrm{AH}=$ acute hypoxia, $\mathrm{AC}=$ air control. Bars: mean with SEM. Scale bars: $50 \mu \mathrm{m}$. 
total antioxidant capacity in the plasma of AH-exposed mice. The effects of increased oxidative stress in the hypoxia-exposed (and in the MDA-fed) animals were also quantified through HPLC analysis of 8-oxo-dG lesions. These lesions are known to induce $\mathrm{GC} \rightarrow \mathrm{TA}$ transversions $[18]$ and have been previously used as a measure of oxidative stress induced by hypoxia and as a marker of oxidative stress in breast cancer patients [38,42]. Our HPLC analyses of breast tumour tissue were consistent with the results of the TBARS and antioxidant assays and showed greater numbers of 8-oxo-dG lesions following AH exposure and MDA consumption. We chose to quantify 8-oxo-dG lesions based on their ROS-dependent formation and their ability to induce mutations $[18,43]$. Therefore, one of our underlying assumptions was that increased 8-oxo$\mathrm{dG}$ lesion levels would provide a general indication of potential DNA lesions and hence mutagenic events associated with oxic stress. An alternate approach might have been to quantify specific, tumourigenesis-modifying mutations such as base pair mutations, gene amplifications, chromosomal translocations or aneuploidy directly from tumour biopsies, which would allow comparison of mutation levels with tumourigenesis data on an individual animal basis. However, identifying which are the critical lesions is problematic and the relevant lesions might be different in different tumours in the same animal, complicating the analysis.

Together, our results provide in vivo evidence that the cyclic hypoxia-breathing regime causes significant oxidative stress and might be expected to induce genomic instability and tumour progression. However, despite the increase in oxidative stress we observed little change in tumour progression, although both gassing exposures did significantly reduce primary tumour burdens relative to cage control mice. This is likely due to various extra stressors in the gassed mice such as handling, temporary ( $4 \mathrm{hr}$ ) absence of food and water and exposure to foreign cage mates, conditions that have all been reported to have the potential to modify tumour progression [44-46]. Some of the suggested underlying mechanisms include stressormediated changes in various immune cell and cytokine levels, accelerated telomere shortening and apoptosis induction [46-48].

Although the increases in hypoxia-induced lipid peroxidation and 8-oxo-dG lesions were statistically significant, our data suggests that these changes may not have been large enough to induce a biological impact. Therefore, we treated animals with MDA, which induced greater increases in 8-oxo-dG lesions than those seen with the AH exposure, and assessed the animals for primary and metastatic tumour progression. Despite the significant increase in 8-oxo-dG lesions in MDA-fed mice, again no respective changes in tumour progression were observed. These find- ings suggest that increases in oxidative stress and 8-oxo$\mathrm{dG}$ lesions do not play a significant role in the tumour progression of the MMTV-PyMT model. Similar conclusions have also been reported from experiments with the MMTV-PyMT model where the lack of a significant difference in point mutations between normal, malignant and metastatic tissues and the lack of loss of heterozygosity (LOH) above background levels was attributed to the strong transforming ability of the middle $\mathrm{T}$ oncogene $[49,50]$. This is consistent with the findings that several pathological conditions with increased 8-oxo-dG levels in tissue can occur without tumour incidence and studies that have reported no relationship between DNA adduct levels or even megabase deletions and cancer incidence $[51,52]$. Furthermore, the mouse model deficient in OGG1, a glycosylase responsible for removal of 8-oxo-dG lesions, fails to demonstrate a significant effect on tumourigenesis despite significantly elevated 8-oxo-dG lesions [53,54]. A similar observation has been reported for another glycosylase, $M Y H$, and only when the two mutants are combined or another stressor, such as UV exposure, is introduced is an increase in tumour incidence observed $[55,56]$. Therefore, it is possible that similar compensatory mechanisms could have prevented the hypoxia exposures from translating into changes in tumour progression and that different results could be seen if the gassings were imposed on one of the abovementioned repair-deficient models. Overall, our findings are consistent with the idea that any effect of oxidative stress on tumour progression in the MMTV-PyMT model would require stress levels, which are not inducible by the degrees of cyclic hypoxia or MDA exposures used in this study, and emphasize the importance of the lesion type, location and context in addition to their number.

The 6-week acute hypoxia exposure also resulted in a significant increase in TAMs as detected by the F4/80 MØ marker. TAMs are thought to represent a distinct $M \emptyset$ population, for which phenotypic characterization remains incomplete. They differ in their activity from the $M \varnothing$ populations found in normal tissues and their differentiation depends on the cytokines expressed in the host tumour [57]. Previous work has implicated a multitude of roles for TAMs in tumour progression, including angiogenesis and stimulation of cellular metastasis and survival $[23,58]$. Our data show in vivo evidence of hypoxia-mediated TAM accumulation to tumours, independent of angiogenesis. Although discordances between hypoxia and stimulation of angiogenesis have been reported previously, the absence of increased angiogenesis with increasing TAM content seems to be in contrast to previous reports $[26,59]$. This dissimilarity may be due to the different markers used for angiogenic quantification or varying angiogenic potentials between hypoxia- and CSF-1stimulated TAMs. Although the hypoxia-mediated 
increase in $\mathrm{F} 4 / 80$ positive $\mathrm{MØs} \mathrm{did} \mathrm{not} \mathrm{translate} \mathrm{into}$ increased tumour burden or lung metastases in the MMTV-PyMT model, the lack of specific TAM co-localization to hypoxic areas is consistent with previous observations in the MMTV-PyMT model where no co-localization of TAMs to hypoxic areas, as identified through pimonidazole staining, was observed [34]. In future work, the $\mathrm{AH}$ gassing exposure could be shifted from the period of primary tumour growth to metastasis formation stage since the role of $M \varnothing$ in tumour progression has been shown to occur at the invasion stage of tumour cells where $M \varnothing$ physically interact with cells invading into the vasculature [26].

Although an in vivo study examining the effects of whole body exposure to hypoxia on leukaemia progression reported no significant differences in blood cell counts or cellular proliferation or apoptosis rates of the control mice following daily 18 hour exposure to $10 \%$ oxygen during 30 days, significantly increased levels of the antiangiogenic factor, thrombospondin-1, have been observed in hypoxia-exposed endothelial cells [60,61]. Therefore, one potential limitation of the current model is that the whole animal in addition to the tumour was exposed to cycling hypoxia, which may induce adaptive physiological responses that might be able to neutralize or mask changes occurring at the tumour level.

\section{Conclusion}

We have demonstrated increased 8-oxo-dG DNA lesions following exposure to acute cyclic hypoxia (AH), supporting the concept that tumour hypoxia could have mutagenic potential. However, neither this exposure or treatment with MDA, which caused the greater increase in 8-oxo-dG DNA lesions, affected tumour progression, raising doubts concerning the importance of oxidative stress in tumour progression of the MMTV-PyMT model. In this context, it is of interest that we have obtained similar results in the MMTV-Neu mammary tumour model (Kalliomäki, 2008). Interestingly we also observed that $\mathrm{AH}$ exposure increased TAM content of the PyMT tumours. This increase was not associated with hypoxic areas in the tumours nor did it relate to angiogenesis, one of the putative roles of TAMs. Our current work suggests that this response may be dependent on changes associated with the MMTV-PyMT oncogene since similar hypoxia exposure did not significantly increase the $\mathrm{F} 4 / 80^{+} \mathrm{M} \emptyset$ content of the MMTV-Neu tumours (Kalliomäki, 2008).

\section{Abbreviations}

2-NP: 2-nitropropane, 8-oxo-dG: 8-oxo-7,8-dihydro-2'deoxyguanosine; APE/Ref-1: Apurinic/apyrimidinic endonuclease 1/redox effector factor-1; BER: Base excision repair; BHT: Butylated hydroxytoluene; CAIX: Carbonic anhydrase IX; CXCR4: Chemokine receptor 4; EF5: 2-(2-
nitro-1-H-imidazol-1-yl)- $N$-(2,2,3,3,3-pentafluoropropyl) acetamide; GLUT-1: Glucose transporter 1; HIF-1 $\alpha$ : Hypoxia-inducible factor- $1 \alpha$; HPLC-EC: High performance liquid chromatography with electrochemical detection; IHC: Immunohistochemistry; Ku70: ATP-dependent DNA helicase 2 subunit 1; MDA: Malondialdehyde; MIF: Macrophage inhibitory factor; Mlh1: mutL homolog 1; MMTV: Mouse mammary tumour virus; MØ: Macrophage; MSH2/6: MutS homolog 2/6; O/N: Overnight; PMS2: PMS2 postmeiotic segregation increased 2; PyMT: Polyoma middle T; RAD51: DNA repair protein RAD51 homolog 1; ROS/RNS: Reactive oxygen/nitrogen species; $\mathrm{R} / \mathrm{T}$ : Room temperature; TAM: Tumour-associated macrophage; TBARS: Thiobarbituric acid reactive substance; VEGF: Vascular endothelial growth factor; Xrcc4: X-ray repair cross complementing protein 4 .

\section{Competing interests}

The authors declare that they have no competing interests.

\section{Authors' contributions}

TMK contributed to the design of the experiments, conducted the animal studies and the majority of the statistical analyses, assisted in the HPLC sample preparation and drafted the manuscript. GMcC performed the HPLC analyses and drafted the associated sections of the manuscript. SJL performed part of the hypoxia exposures and critically revised the manuscript. PGW supervised the HPLC studies and critically revised the manuscript. RPH conceived the study, supervised the experiments and helped to draft the manuscript. All authors have read and approved the final manuscript.

\section{Acknowledgements}

The authors would like to thank Melania Pintilie for assistance with the statistical analyses, Dr. Geoffrey Wood and Patrick Subarsky for helpful discussions and Robert Kuba for excellent technical assistance.

\section{References}

I. Milosevic M, Fyles A, Hedley D, Hill R: The human tumor microenvironment: Invasive (needle) measurement of oxygen and interstitial fluid pressure. Semin Radiat Oncol 2004, I4(3):249-258.

2. Dales JP, Garcia S, Meunier-Carpentier S, Andrac-Meyer L, Haddad $\mathrm{O}$, Lavaut MN, Allasia C, Bonnier P, Charpin C: Overexpression of hypoxia-inducible factor HIF-I alpha predicts early relapse in breast cancer: retrospective study in a series of 745 patients. Int J Cancer 2005, I I 6(5):734-739.

3. Tomes L, Emberley E, Niu Y, Troup S, Pastorek J, Strange K, Harris A, Watson PH: Necrosis and hypoxia in invasive breast carcinoma. Breast Cancer Res Treat 2003, 8I (I):61-69.

4. Cairns RA, Kalliomaki T, Hill RP: Acute (cyclic) hypoxia enhances spontaneous metastasis of KHT murine tumors. Cancer Res 2001, 6 I (24):8903-8908.

5. Rofstad EK, Galappathi K, Mathiesen B, Ruud EB: Fluctuating and diffusion-limited hypoxia in hypoxia-induced metastasis. Clin Cancer Res 2007, I3(7): I97|-1978.

6. Reynolds TY, Rockwell S, Glazer PM: Genetic instability induced by the tumor microenvironment. Cancer Res 1996, 56(24):5754-5757. 
7. Rofstad EK, Johnsen NM, Lyng H: Hypoxia-induced tetraploidisation of a diploid human melanoma cell line in vitro. $\mathrm{Br} J$ Cancer Suppl 1996, 27:S136-9.

8. Young SD, Marshall RS, Hill RP: Hypoxia induces DNA overreplication and enhances metastatic potential of murine tumor cells. Proc Natl Acad Sci U S A 1988, 85(24):9533-9537.

9. Coquelle A, Toledo F, Stern S, Bieth A, Debatisse M: A new role for hypoxia in tumor progression: induction of fragile site triggering genomic rearrangements and formation of complex DMs and HSRs. Mol Cell 1998, 2(2):259-265.

10. Huang LE, Bindra RS, Glazer PM, Harris AL: Hypoxia-induced genetic instability--a calculated mechanism underlying tumor progression. J Mol Med 2007, 85(2): 139-148.

II. Bindra RS, Schaffer PJ, Meng A, Woo J, Maseide K, Roth ME, Lizardi P, Hedley DW, Bristow RG, Glazer PM: Alterations in DNA repair gene expression under hypoxia: elucidating the mechanisms of hypoxia-induced genetic instability. Ann N Y Acad Sci 2005, 1059: 184-195.

12. Meng AX, Jalali F, Cuddihy A, Chan N, Bindra RS, Glazer PM, Bristow RG: Hypoxia down-regulates DNA double strand break repair gene expression in prostate cancer cells. Radiother Oncol 2005, 76(2): 168-176.

13. Bristow RG, Hill RP: Hypoxia and metabolism. Hypoxia, DNA repair and genetic instability. Nat Rev Cancer 2008, 8(3): $180-192$.

14. Jackson AL, Loeb LA: The contribution of endogenous sources of DNA damage to the multiple mutations in cancer. Mutat Res 200I, 477(I-2):7-2I.

15. Fukumura $D$, Kashiwagi $S$, Jain RK: The role of nitric oxide in tumour progression. Nat Rev Cancer 2006, 6(7):52I-534.

16. Li C, Jackson RM: Reactive species mechanisms of cellular hypoxia-reoxygenation injury. Am J Physiol Cell Physiol 2002, 282(2): $C 227-41$.

17. Brown NS, Bicknell R: Hypoxia and oxidative stress in breast cancer. Oxidative stress: its effects on the growth, metastatic potential and response to therapy of breast cancer. Breast Cancer Res 200I, 3(5):323-7. Epub 200 I Jul 23..

18. Malins DC, Polissar NL, Ostrander GK, Vinson MA: Single 8-oxoguanine and 8-oxo-adenine lesions induce marked changes in the backbone structure of a 25-base DNA strand. Proc Natl Acad Sci U S A 2000, 97(23): $12442-12445$.

19. VanderVeen LA, Hashim MF, Shyr Y, Marnett LJ: Induction of frameshift and base pair substitution mutations by the major DNA adduct of the endogenous carcinogen malondialdehyde. Proc Natl Acad Sci U S A 2003, I00(24): | 4247-I 4252

20. de Zwart LL, Meerman JH, Commandeur JN, Vermeulen NP: Biomarkers of free radical damage applications in experimental animals and in humans. Free Radic Biol Med 1999, 26(12):202-226.

21. Murdoch C, Giannoudis A, Lewis CE: Mechanisms regulating the recruitment of macrophages into hypoxic areas of tumors and other ischemic tissues. Blood 2004, 104(8):2224-2234.

22. Kim HW, Murakami A, Williams MV, Ohigashi H: Mutagenicity of reactive oxygen and nitrogen species as detected by co-culture of activated inflammatory leukocytes and AS52 cells. Carcinogenesis 2003, 24(2):235-24I.

23. Murdoch $C$, Muthana M, Lewis CE: Hypoxia regulates macrophage functions in inflammation. J Immunol 2005, I 75( I 0):6257-6263.

24. Bingle L, Brown NJ, Lewis CE: The role of tumour-associated macrophages in tumour progression: implications for new anticancer therapies. J Pathol 2002, 196(3):254-265.

25. Lin EY, Nguyen AV, Russell RG, Pollard JW: Colony-stimulating factor I promotes progression of mammary tumors to malignancy. J Exp Med 200I, 193(6):727-740.

26. Wyckoff JB, Wang Y, Lin EY, Li JF, Goswami S, Stanley ER, Segall JE, Pollard JW, Condeelis J: Direct visualization of macrophageassisted tumor cell intravasation in mammary tumors. Cancer Res 2007, 67(6):2649-2656.

27. Guy CT, Cardiff RD, Muller WJ: Induction of mammary tumors by expression of polyomavirus middle $T$ oncogene: a transgenic mouse model for metastatic disease. Mol Cell Biol 1992, i2(3):954-96I.

28. Siu GM, Draper HH, Valli VE: Oral toxicity of malonaldehyde: a 90-day study on mice. I Toxicol Environ Health 1983, II(I):105-II9.
29. Cabelof DC, Raffoul J], Yanamadala S, Guo Z, Heydari AR: Induction of DNA polymerase beta-dependent base excision repair in response to oxidative stress in vivo. Carcinogenesis 2002, 23(9): $14 \mid 9-1425$.

30. Hedley D, Chow S: Flow cytometric measurement of lipid peroxidation in vital cells using parinaric acid. Cytometry 1992, 13(7):686-692.

3I. Ravanat JL, Douki T, Duez P, Gremaud E, Herbert K, Hofer T, Lasserre L, Saint-Pierre C, Favier A, Cadet J: Cellular background level of 8-oxo-7,8-dihydro-2'-deoxyguanosine: an isotope based method to evaluate artefactual oxidation of DNA during its extraction and subsequent work-up. Carcinogenesis 2002. 23(II): $1911-1918$.

32. Evans AR, Limp-Foster M, Kelley MR: Going APE over ref-I. Mutat Res 2000, 46I(2):83-I08.

33. Crowther M, Brown NJ, Bishop ET, Lewis CE: Microenvironmental influence on macrophage regulation of angiogenesis in wounds and malignant tumors. I Leukoc Biol 200I, 70(4):478-490

34. Lin EY, Li JF, Gnatovskiy L, Deng Y, Zhu L, Grzesik DA, Qian H, Xue $\mathrm{XN}$, Pollard JW: Macrophages regulate the angiogenic switch in a mouse model of breast cancer. Cancer Res 2006 , 66(23): I | 238- I I 246

35. Cairns RA, Hill RP: Acute hypoxia enhances spontaneous lymph node metastasis in an orthotopic murine model of human cervical carcinoma. Cancer Res 2004, 64(6):2054-206I.

36. Subarsky P, Hill RP: The hypoxic tumour microenvironment and metastatic progression. Clin Exp Metastasis 2003, 20(3):237-250

37. Liao D, Corle C, Seagroves TN, Johnson RS: Hypoxia-inducible factor-Ialpha is a key regulator of metastasis in a transgenic model of cancer initiation and progression. Cancer Res 2007, 67(2):563-572.

38. Moller P, Loft S, Lundby C, Olsen NV: Acute hypoxia and hypoxic exercise induce DNA strand breaks and oxidative DNA damage in humans. Faseb J 200I, I5(7): $1181-1186$.

39. Ray G, Batra S, Shukla NK, Deo S, Raina V, Ashok S, Husain SA: Lipid peroxidation, free radical production and antioxidant status in breast cancer. Breast Cancer Res Treat 2000, 59(2):163-170.

40. Mori K, Shibanuma M, Nose K: Invasive Potential Induced under Long-Term Oxidative Stress in Mammary Epithelial Cells. Cancer Res 2004, 64(20):7464-7472.

4I. Malins DC, Polissar NL, Gunselman SJ: Progression of human breast cancers to the metastatic state is linked to hydroxyl radical-induced DNA damage. Proc Natl Acad Sci U S A 1996, 93(6):2557-2563

42. Matsui A, lkeda T, Enomoto K, Hosoda K, Nakashima H, Omae K, Watanabe M, Hibi T, Kitajima M: Increased formation of oxidative DNA damage, 8-hydroxy-2'-deoxyguanosine, in human breast cancer tissue and its relationship to GSTPI and COMT genotypes. Cancer Lett 2000, I 5 I (I):87-95

43. Cadet J, Douki T, Gasparutto D, Ravanat JL: Oxidative damage to DNA: formation, measurement and biochemical features. Mutat Res 2003, 53 I ( I-2):5-23.

44. Kerr LR, Wilkinson DA, Emerman JT, Weinberg J: Interactive effects of psychosocial stressors and gender on mouse mammary tumor growth. Physiol Behav 1999, 66(2):277-284.

45. Pape-Ansorge KA, Grande JP, Christensen TA, Maihle NJ, Cleary MP: Effect of moderate caloric restriction and/or weight cycling on mammary tumor incidence and latency in MMTV-Neu female mice. Nutr Cancer 2002, 44(2): 162-168.

46. Thaker PH, Han LY, Kamat AA, Arevalo JM, Takahashi R, Lu C, Jennings NB, Armaiz-Pena G, Bankson JA, Ravoori M, Merritt WM, Lin YG, Mangala LS, Kim TJ, Coleman RL, Landen CN, Li Y, Felix E, Sanguino AM, Newman RA, Lloyd M, Gershenson DM, Kundra V, LopezBerestein G, Lutgendorf SK, Cole SW, Sood AK: Chronic stress promotes tumor growth and angiogenesis in a mouse model of ovarian carcinoma. Nat Med 2006, I 2(8):939-944.

47. Epel ES, Blackburn EH, Lin J, Dhabhar FS, Adler NE, Morrow JD, Cawthon RM: From the Cover: Accelerated telomere shortening in response to life stress. PNAS 2004, 101 (49): 173 I2-173I5.

48. Thompson HJ, Zhu Z, Jiang W: Identification of the apoptosis activation cascade induced in mammary carcinomas by energy restriction. Cancer Res 2004, 64(4): I54I- 1545.

49. Jakubczak JL, Merlino G, French JE, Muller W], Paul B, Adhya S, Garges $\mathrm{S}$ : Analysis of genetic instability during mammary tumor pro- 
gression using a novel selection-based assay for in vivo mutations in a bacteriophage lambda transgene target. Proc Natl Acad Sci U S A 1996, 93(1 7):9073-9078.

50. Ritland SR, Rowse GJ, Chang Y, Gendler SJ: Loss of heterozygosity analysis in primary mammary tumors and lung metastases of MMTV-MTAg and MMTV-neu transgenic mice. Cancer Res I 997, 57( I 6):3520-3525.

5I. Nagao M, Ochiai M, Okochi E, Ushijima T, Sugimura T: Lacl transgenic animal study: relationships among DNA-adduct levels, mutant frequencies and cancer incidences. Mutat Res 200I, 477(1-2): I 19-124.

52. Nobrega MA, Zhu Y, Plajzer-Frick I, Afzal V, Rubin EM: Megabase deletions of gene deserts result in viable mice. Nature 2004, 43 I (70 I I): $988-993$.

53. Klungland A, Rosewell I, Hollenbach S, Larsen E, Daly G, Epe B, Seeberg E, Lindahl T, Barnes DE: Accumulation of premutagenic DNA lesions in mice defective in removal of oxidative base damage. Proc Natl Acad Sci U S A 1999, 96(23): I 3300-I 3305.

54. Minowa $O$, Arai $T$, Hirano $M$, Monden $Y$, Nakai S, Fukuda M, Itoh $M$, Takano H, Hippou Y, Aburatani H, Masumura K, Nohmi T, Nishimura $\mathrm{S}$, Noda $\mathrm{T}: \mathrm{Mmh} / \mathrm{Ogg} \mathrm{I}$ gene inactivation results in accumulation of 8-hydroxyguanine in mice. Proc Natl Acad Sci U S A 2000, 97(8):4|56-4|6I.

55. Xie Y, Yang H, Cunanan C, Okamoto K, Shibata D, Pan J, Barnes DE, Lindahl T, Mcllhatton M, Fishel R, Miller JH: Deficiencies in mouse Myh and OggI result in tumor predisposition and $G$ to $T$ mutations in codon $\mathbf{I} 2$ of the K-ras oncogene in lung tumors. Cancer Res 2004, 64(9):3096-3102.

56. Kunisada M, Sakumi K, Tominaga Y, Budiyanto A, Ueda M, Ichihashi $M$, Nakabeppu $Y$, Nishigori C: 8-Oxoguanine formation induced by chronic UVB exposure makes Ogg I knockout mice susceptible to skin carcinogenesis. Cancer Res 2005, 65(14):6006-6010.

57. Sica A, Schioppa T, Mantovani A, Allavena P: Tumour-associated macrophages are a distinct $M 2$ polarised population promoting tumour progression: potential targets of anti-cancer therapy. Eur J Cancer 2006, 42(6):7I7-727.

58. Condeelis J, Pollard JW: Macrophages: obligate partners for tumor cell migration, invasion, and metastasis. Cell 2006, I 24(2):263-266.

59. Moeller BJ, Cao Y, Vujaskovic Z, Li CY, Haroon ZA, Dewhirst MW: The relationship between hypoxia and angiogenesis. Semin Radiat Oncol 2004, I 4(3):2I 5-22I.

60. Liu W, Guo M, Xu YB, Li D, Zhou ZN, Wu YL, Chen Z, Kogan SC, Chen GQ: Induction of tumor arrest and differentiation with prolonged survival by intermittent hypoxia in a mouse model of acute myeloid leukemia. Blood 2006, I 07(2):698-707.

6I. Phelan MW, Forman LW, Perrine SP, Faller DV: Hypoxia increase thrombospondin-I transcript and protein in cultured endothelial cells. J Lab Clin Med 1998, I 32(6):519-529.

\section{Pre-publication history}

The pre-publication history for this paper can be accessed here:

http://www.biomedcentral.com/1471-2407/8/151/pre pub
Publish with Biomed Central and every scientist can read your work free of charge

"BioMed Central will be the most significant development for disseminating the results of biomedical research in our lifetime. "

Sir Paul Nurse, Cancer Research UK

Your research papers will be:

- available free of charge to the entire biomedical community

- peer reviewed and published immediately upon acceptance

- cited in PubMed and archived on PubMed Central

- yours - you keep the copyright
BioMedcentral 